immunocompromised patients. Cochrane Database Syst Rev. 2014;2014:CD005590. https://doi.org/10.1002/

14651858.CD005590.pub3

2. Shannon K, Pasikhova Y, Ibekweh Q, Ludlow S, Baluch A. Nocardiosis following hematopoietic stem cell transplantation. Transpl Infect Dis. 2016;18:169-75. https://doi.org/10.1111/tid.12499

3. Wallace RJ, Septimus EJ, Williams TW, Conklin RH, Satterwhite TK, Bushby MB, et al. Use of trimethoprimsulfamethoxazole for treatment of infections due to Nocardia. Rev Infect Dis. 1982;4:315-25. https:/ / doi.org/ 10.1093/clinids/4.2.315

4. Epstein DJ, Benamu E, Subramanian AK. Use of alternative agents for prevention of opportunistic infections in heart and lung transplant recipients. Clin Infect Dis. 2018;67:1637-9. PubMed https://doi.org/10.1093/cid/ciy397

5. Urbancic KF, Ierino F, Phillips E, Mount PF, Mahony A, Trubiano JA. Taking the challenge: A protocolized approach to optimize Pneumocystis pneumonia prophylaxis in renal transplant recipients. Am J Transplant. 2018;18:4626. PubMed https://doi.org/10.1111/ajt.14498

6. Coussement J, Lebeaux D, van Delden C, Guillot H, Freund R, Marbus S, et al. Nocardia infection in solid organ transplant recipients: a multicenter European case-control study. Clin Infect Dis. 2016;63:338-45. https://doi.org/10.1093/cid/ciw241

7. Hemmersbach-Miller M, Stout JE, Woodworth MH, Cox GM, Saullo JL. Nocardia infections in the transplanted host. Transpl Infect Dis. 2018;20:e12902. https:/ / doi.org/ 10.1111/tid.12902

8. Filice GA. Nocardiosis in persons with human immunodeficiency virus infection, transplant recipients, and large, geographically defined populations. J Lab Clin Med. 2005;145:156-62. https://doi.org/10.1016/j.lab.2005.01.002

9. Baneman E, Kim N, Rana M, Renteria AS, Steinberg AS, Jakubowski RM, et al. Optimizing the use of trimethoprimsulfamethoxazole for prevention of PCP and opportunistic infections in allogeneic hematopoietic cell transplant recipients. J Clin Oncol. 2018;36:138. https:/ / doi.org/ 10.1200/JCO.2018.36.30_suppl.138

Address for correspondence: Alfredo G. Puing, Division of Infectious Diseases, Department of Medicine, City of Hope National Medical Center, 1500 E Duarte Rd, Modular 1 West, Duarte, CA 91010, USA; email: apuing@coh.org

\section{Autochthonous Case of Rickettsia slovaca Infection in Russia}

\author{
Ruslan F. Sayfullin, Nadezhda E. Perekopskaya, \\ Ludmila S. Karan, Nadezhda N. Zvereva, \\ Muhammad A. Sayfullin \\ Author affiliations: Municipal Clinical Hospital No 52, Moscow, \\ Russia (R.F. Sayfullin); Pirogov Russian National Research \\ Medical University, Moscow (R.F. Sayfullin, N.N. Zvereva, \\ M.A. Sayfullin); Infectious Clinical Hospital No. 1, Moscow \\ (N.E. Perekopskaya); Central Scientific Research Institute of \\ Epidemiology, Moscow (L.S. Karan); Gamaleya Institute of \\ Epidemiology and Microbiology, Moscow (M.A. Sayfullin).
}

DOI: https://doi.org/10.3201/eid2710.204621

We describe an autochthonous case of Rickettsia slovaca infection in a man 35 years of age from Russia who had tickborne lymphadenopathy. We used ELISA and quantitative PCR testing to further identify DNA and confirm diagnosis. Physicians in Russia should consider similar diseases in differential diagnoses after tick bites.

$R$ ickettsia slovaca was isolated in Dermacentor marginatus ticks in 1968 in Slovakia and recognized as a Rickettsia species with unknown pathogenicity. In 1997, a study described the first laboratory-confirmed case of Rickettsia slovaca infection in a human (1). R. slovaca has been detected in ticks in many countries in Europe, including the Mediterranean region. Human cases of syndromes that can be caused by $R$. slovaca, including tickborne lymphadenopathy (TIBOLA), Dermacentorborne necrosis-erythema-lymphadenopathy (DEBONEL), and scalp eschar and neck lymphadenopathy after tick bite (SENLAT) have been reported $(2,3)$. $R$. slovaca has been detected in ticks in 4 of 85 regions of Russia (Figure), and 1 imported case of $R$. slovaca infection was reported (4-7). The aim of our study was to describe an autochthonous case of $R$. slovaca infection in a man in Russia.

In May 2019, a 35-year-old male resident of Russia with an unremarkable medical history sought treatment for eschar on the skin of his right shin, painful and enlarged inguinal lymph nodes, rash, pain in his right knee, and severe fatigue. Before onset, he was in a rural village in the Voronezh region of Russia for 8 days, where he had contact with domestic animals and later noticed an insect bite near the location of the eschar. He reported no history of foreign travel in the previous 6 months. 
Disease onset began with an ulcer, $2-3 \mathrm{~cm}$ in diameter, on his right shin. By days $3-4$, the ulcer became an eschar, and the patient experienced chills and sweats at night. By days 5-6, chills and sweats remained, and an erythema up to $5 \mathrm{~cm}$ in diameter appeared around the eschar. The patient also noticed pain in his right knee, papular rash on his right leg and the right side of his trunk and neck, and enlarged and painful inguinal and axillary lymph nodes. On day 6, he was examined by a surgeon, who suspected a skin infection and initiated amoxicillin $(1.5 \mathrm{~g} / \mathrm{d})$. On days $7-8$, the rash spread to other limbs, lymph nodes in his neck became painful and enlarged, the pain in his right knee worsened, and low-grade fever $\left(37.4^{\circ} \mathrm{C}-37.6^{\circ} \mathrm{C}\right)$ developed.

On day 8 after symptom onset, he was hospitalized at Infectious Clinical Hospital No. 1 in Moscow. At admission, he had a black eschar surrounded by erythema on the upper part of his right shin and vesiculopapular rash on his limbs and trunk concentrated around the eschar and on the skin of the right knee; in addition, there was bright hyperemia of previously existing scratches. Inguinal, axillary, and neck lymph nodes were painful by palpation and enlarged to $1.5-2.0 \mathrm{~cm}$; his right knee was enlarged and painful by palpation and had impaired range of motion. We found no abnormalities from complete blood count and urinalysis on admission. We suspected skin and soft tissue infection with knee arthritis and changed antimicrobial therapy to ceftriaxone $(2.0 \mathrm{~g} / \mathrm{d})$ and metronidazole $(1.5 \mathrm{~g} / \mathrm{d})$.

On day 10, his body temperature normalized and the erythema around the eschar faded, but the rash continued to spread (Appendix, https://wwwnc.cdc.
gov/EID/article/27/10/20-4621-App1.pdf) and the pain in his knee worsened. He had slightly elevated C-reactive protein (12 mg/L; reference $<5 \mathrm{mg} / \mathrm{L})$, but urine and blood cultures showed no growths. Taking into account anamnesis and a black eschar typical of TIBOLA, DEBONEL, and SENLAT syndromes, we suspected rickettsiosis. We detected Rickettsia DNA, but only in the sample from the eschar swab sample. We confirmed $R$. slovaca infection by molecular assay on blood and the eschar swab samples, collected on day 10 after disease onset (Appendix). We extracted DNA using a QIAGEN DNeasy blood and tissue kit (https:/ / www.qiagen.com) and tested it with an AmpliSens Rickettsia spp. SFG-FL real-time PCR kit (https:// www.amplisens.ru). For further confirmation, we used DNA isolated from the swab to sequence partial OmpA (primers Rr190.70p, Rr190.701n) and gltA (primers RpCS.877p, RpCS.1258n) genes (8).

We changed the patient's antimicrobial therapy to doxycycline $(0.2 \mathrm{~g} / \mathrm{d})$, and his health improved rapidly. By day 15, pain and edema in his right knee had regressed, the rash had faded, and the eschar had begun to heal. The patient was discharged, but continued taking doxycycline for 10 additional days.

By 2 months after disease onset, the eschar and a few elements of papular rash around it had completely disappeared, but substantial fatigue remained for up to 5 months. For serologic assays, we collected serum samples on days 10, 30, and 160 after disease onset and tested for Rickettsia IgM and IgG using a Vircell Rickettsia conorii ELISA IgG/IgM kit (https://www. vircell.com). The lack of serologic response that we observed may have been related to the sensitivity of

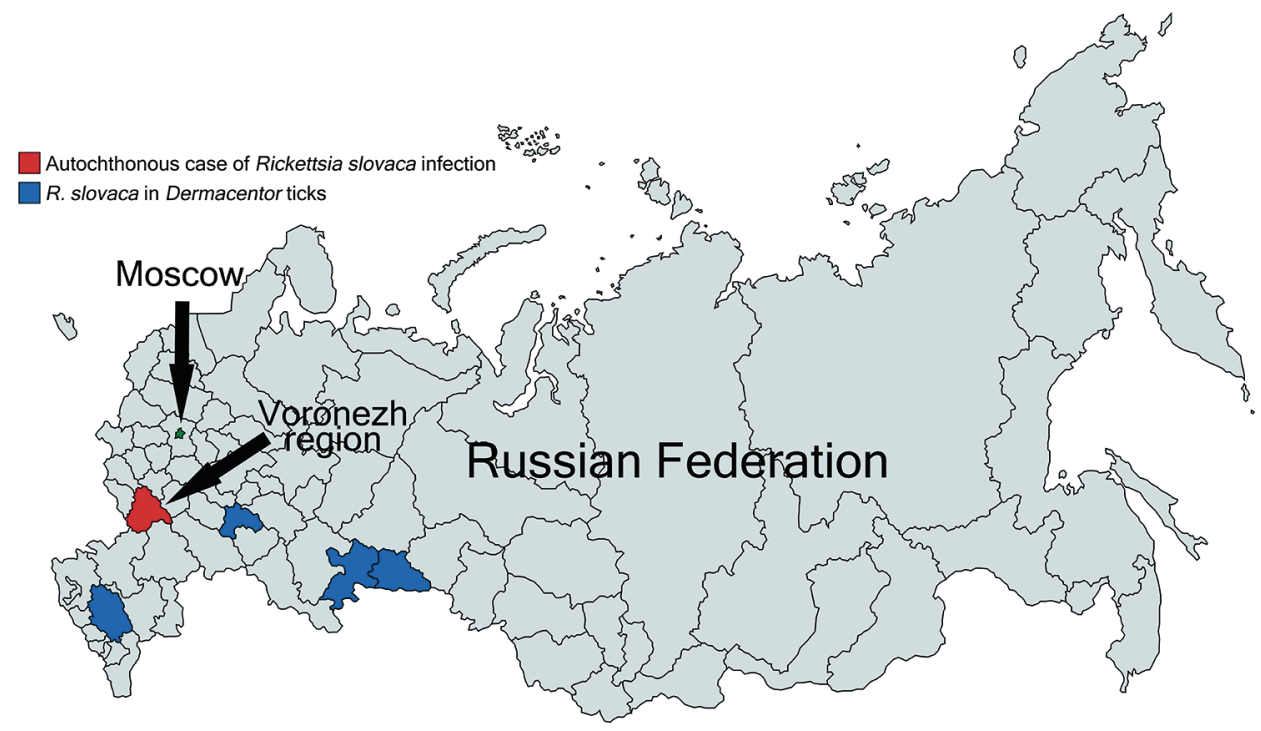

Figure. Regions in Russia where Rickettsia slovaca was detected only in ticks and the region where an autochthonous human case of $R$. slovaca infection was registered. 
the ELISA test we used (9). On the basis of our findings, physicians should consider TIBOLA, DEBONEL, and SENLAT syndromes in differential diagnoses after tick bites occurring in Russia.

\section{About the Author}

Dr. R.F. Sayfullin is an assistant professor of children's infectious diseases at the Pirogov Russian National Research Medical University and a pathologist in Municipal Clinical Hospital No. 52 in Moscow, Russia. His research interests include tick-borne infections, tropical diseases, and travel medicine.

\section{References}

1. Raoult D, Berbis P, Roux V, Xu W, Maurin M. A new tick-transmitted disease due to Rickettsia slovaca. Lancet. 1997;350:112-3. https://doi.org/10.1016/ S0140-6736(05)61814-4

2. Parola P, Paddock CD, Socolovschi C, Labruna MB, Mediannikov O, Kernif T, et al. Update on tick-borne rickettsioses around the world: a geographic approach. Clin Microbiol Rev. 2013;26:657-702. https:/ / doi.org/10.1128/ CMR.00032-13

3. Oteo JA, Portillo A. Tick-borne rickettsioses in Europe. Ticks Tick Borne Dis. 2012;3:271-8. https:/ / doi.org/ 10.1016/j.ttbdis.2012.10.035

4. Rudakov NV, Shpynov SN, Yastrebov VK, Samoylenko IE, Kumpan LV, Reshetnikova TA, et al. The present state of the problem of rickettsioses in Russia and new approaches to the classification of diseases caused by spotted fever group Rickettsiae [in Russian]. Acta Biomedica Scientifica. 2012;5:109-13.

5. Shpynov SN, Rudakov NV, Fournier PE, Raoult D. Molecular typing of Rickettsiae, Anaplasmae, and Ehrlichiae in ticks in the Russian Federation and the Republic of Kazakhstan [in Russian]. Zdorov'e Naseleniya i Sreda Obitaniya. 2012;1:33-5.

6. Igolkina YP, Fomenko NV, Livanova NN, Astanin VB, Gosteeva LA, Chernousova NY, et al. Identification of various types of Rickettsia in Ixodes mites, in the blood of humans and small mammals in the south of western Siberia and the Urals [in Russian]. Bulletin of Siberian Medicine. 2006;5:121-5. https:/ / doi.org/10.20538/1682-0363-2006--121-125

7. Tarasevich IV, Saifullin MA, Luchshev AV, Pantyukhina AN, Mazankova LN, Dudina KR, et al. Imported rickettsial diseases detected in Moscow among tourists from endemic foci [in Russian]. Epidemiology and Infectious Diseases. 2015:55-61.

8. Portillo A, de Sousa R, Santibáñez S, Duarte A, Edouard S, Fonseca IP, et al. Guidelines for the detection of Rickettsia spp. Vector Borne Zoonotic Dis. 2017;17:23-32. https://doi.org/10.1089/vbz.2016.1966

9. Santibáñez S, Ibarra V, Portillo A, Blanco JR, Martínez de Artola V, Guerrero A, et al. Evaluation of IgG antibody response against Rickettsia conorii and Rickettsia slovaca in patients with DEBONEL/TIBOLA. Ann N Y Acad Sci. 2006;1078:570-2. https://doi.org/10.1196/ annals.1374.113

Address for correspondence: Ruslan Sayfullin, Pirogov Russian National Research Medical University, Ostrityanova, 1, 117997, Moscow, Russia; email: ppsaifullin@rambler.ru

\section{Equine Herpesvirus 1 Variant and New Marker for Epidemiologic Surveillance, Europe, 2021}

\author{
Gabrielle Sutton, Camille Normand, \\ Flora Carnet, Anne Couroucé, Marie Garvey, \\ Sophie Castagnet, Christine I. Fortier, Erika S. Hue, \\ Christel Marcillaud-Pitel, Loïc Legrand, \\ Romain Paillot, Pierre-Hugues Pitel, Ann Cullinane, \\ Stéphane Pronost
}

Author affiliations: University of Caen Normandy, Caen, France (G. Sutton, C. Normand, F. Carnet, A. Couroucé, C.I. Fortier, E.S. Hue, L. Legrand, S. Pronost); LABÉO Frank Duncombe, Saint-Contest, France (G. Sutton, C. Normand, F. Carnet, S. Castagnet, C.I. Fortier, E.S. Hue, L. Legrand, R. Paillot, P.-H. Pitel, S. Pronost); Cisco-Oniris, Nantes, France (A. Couroucé); Irish Equine Centre, Johnstown, Naas, Ireland (M. Garvey, A. Cullinane); Réseau d'Épidémio-Surveillance en Pathologie Équine, Saint-Contest (C. Marcillaud-Pitel, L. Legrand, P.-H. Pitel, S. Pronost); Writtle University College, Chelmsford, UK (R. Paillot)

\section{DOI: https://doi.org/10.3201/eid2710.210704}

Equine herpesvirus 1 isolates from a 2021 outbreak of neurologic disease in Europe have a mutation, A713G, in open reading frame 11 not detected in 249 other sequences from equine herpesvirus 1 isolates. This singlenucleotide polymorphism could help identify horses infected with the virus strain linked to this outbreak.

$\mathrm{E}$ quine herpesvirus 1 (EHV-1) is a threat to the equine industry, as demonstrated by the ongoing outbreak of neurologic disease initially reported at a large equestrian event in Valencia, Spain. EHV-1 infection is associated with respiratory disease, abortion in mares, neonatal death of foals, ocular disease, and, more rarely, encephalomyelopathy. As of March 26, 2021, a total of 18 horses had died during the outbreak: 11 in Spain, 5 in Germany, and 2 in Belgium. As the horses have returned from Spain to their training yards, the virus has spread to 9 other countries in Europe and to Qatar.

EHV-1 is endemic in horse populations worldwide. Reactivation of latent virus can occur at any time, but infected horses are more vulnerable when exposed to stress. When an outbreak occurs during an equestrian event and horses return to their respective countries or regions, the emergence of new cases of EHV-1 in the weeks and months after often elicits questions regarding the involvement of the strain from the original outbreak. 